\title{
The giant barrel sponge facilitates the recovery of coral fragments after a tropical storm in Taiwan
}

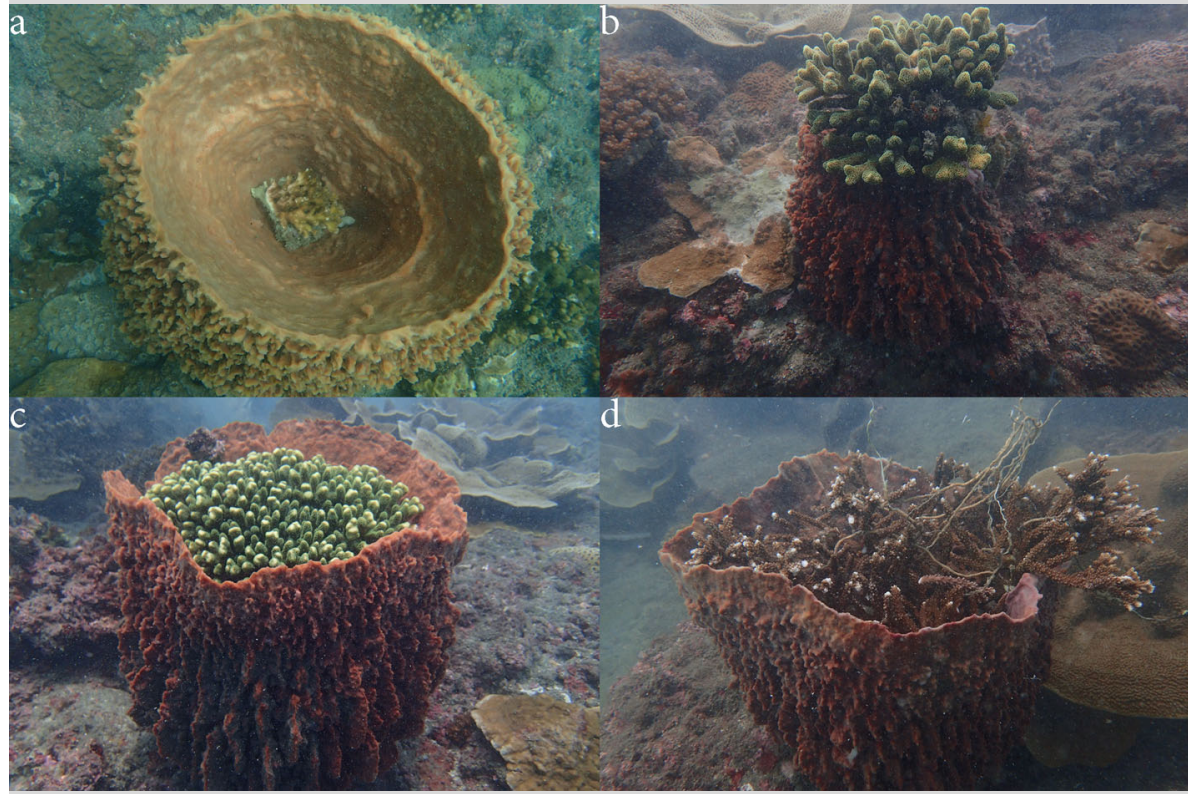

Fig. 1 Photographs of new (a) and adult (b-d) coral fragments growing inside the Pacific giant barrel sponge Xestospongia testudinaria
Observations conducted in the aftermath of typhoon Soudelor (category 5) at the site Fongguie, Taiwan $\left(23^{\circ} 32^{\prime} 16 \mathrm{~N}, 119^{\circ} 32^{\prime} 41 \mathrm{E}\right)$, revealed extensive reef degradation. Corals and sponges were knocked over or broken, and many coral fragments were spread across the reef. Some of these fragments, mainly Porites, Acropora and Pocillopora, had wound up inside the oscules of locally abundant giant barrel sponges (Xestospongia testudinaria). This phenomenon, where new coral fragments were lying in the sponges' osculum, was observed multiple times (Fig. 1a). Other giant barrel sponges had large adult branching and plating coral colonies growing in their osculum (Fig. 1b-d), presumably representing growth of fragments deposited inside the sponges during previous storms.

The sponges harboring large coral colonies were morphologically dis-

torted but did not seem to be affected by the presence of these corals. Tests with fluorescent dye indicated the sponges still had a functioning pumping system, even when the osculum was entirely covered by the coral. In the Caribbean, Xestospongia muta, has been observed to offer stony corals shelter from strong hydrodynamic forces (Hammerman and Garcia-Hernandez 2016). It seems that under the right circumstances coral larvae or coral fragments can find refuge in or on giant barrel sponges, and in the case of Taiwan the presence of the giant barrel sponges seems to enhance coral reef recovery after tropical storms.

Acknowledgements The research was funded by NWO-Aspasia Grant 015.010.030 and MOST 105-2621-B-346-002, Taiwan.

Open Access This article is distributed under the terms of the Creative Commons Attribution 4.0 International License (http:// creativecommons.org/licenses/by/4.0/), which permits unrestricted use, distribution, and reproduction in any medium, provided you give appropriate credit to the original author(s) and the source, provide a link to the Creative Commons license, and indicate if changes were made.

\section{Reference}

Hammerman NM, Garcia-Hernandez JE (2016) The sponge Xestospongia muta offers shelter to the stony coral Madracis auretenra (Northwest Puerto Rico). Marine Biodiversity 47(1):57-58

T. Swierts $(\bowtie) \cdot$ N. J. de Voogd

Marine Biodiversity, Naturalis Biodiversity Center, P.O. Box 9517, 2300 RA Leiden, The Netherlands

e-mail: Thomas.Swierts@naturalis.nl

T. Swierts · N. J. de Voogd

Institute of Environmental Sciences, Leiden University, P.O. Box 9518, 2300 RA Leiden, The Netherlands

Y. M. Huang

Department of Marine Recreation, National Penghu University of Science and Technology, Penghu 88046, Taiwan 